J. Clin. Chem. Clin. Biochem.

Vol. 25, 1987, pp. 241-244

(C) 1987 Walter de Gruyter \& Co. Berlin · New York

\title{
A Fully Automated Method for Sample Clean-Up Prior to Chromatographic and Immunological Analysis
}

\author{
By T.K. Dhar ${ }^{1}$ ) and M. Schöneshöfer \\ Institut für Klinische Chemie und Biochemie, Klinikum Charlottenburg der Freien Universität Berlin
}

(Received September 9/December 2, 1986)

Summary: A fully automated technique for the extraction and clean-up of low-molecular weight analytes from human serum and urine is presented. Its efficiency for sample clean-up prior to immunological assay is demonstrated for six adrenal and gonadal steroid hormones, calcidiol and the peptide hormones gastrin, insulin and glucagon. A more intensive sample clean-up, which is mandatory for liquid chromatographic analysis, is reported for serum cortisol. With the exception of calcidiol, the extraction of steroids is almost complete. Recovery of peptides is about $80 \%$ and depends on the nature of the peptide and on proteinanalyte dissociating diluents. Precision of recovery is lower than $7 \%(\mathrm{CV})$ for all analytes studied. One hundred serum or urine samples can be cleaned up without loss of efficiency by only one solid-phase cartridge. The technique is in principle applicable to all other analytes with physico-chemical structures similar to the analytes in the present study.

\section{Introduction}

The concentration and clean-up of low-concentration analytes from a complex biological matrix is an elemental challenge in many immunological and, particularily, in chromatographic assays. In the recent past, many techniques have been elaborated that may decrease the labour and the time involved as well as improve the assay speed and reliability of the classical manual extraction techniques. A considerable step forward was the introduction of commercial mini-column techniques based on the extraction of solutes from solid matrices such as the "JETUBE" (1), the Extrelut $(2-5)$, the Sep-Pak $(6-7)$, the Chrom Prep (8) or Carbopack (9) technique. Of these, the Sep-Pak $C_{18}$ cartridges seem to be most widely used for rapid sample preparation prior to quantification. The following disadvantages are still inherent in this and all the other solid-phase techniques:

\footnotetext{
1) Present address: Indian Institute of Chemical Biology, Jadavpur, Calcutta-32, India.
}

a) each sample must be manually handled for extractions,

b) more complex elution sequences are not practicable,

c) the relatively expensive cartridges are generally used in "one-way" mode and

d) each new cartridge has to be activated prior to extraction.

We have developed a fully automated sample cleanup procedure, which aims to eliminate most of these disadvantages. We demonstrate its practicability for the clean-up of steroid and peptide hormones from human serum and urine prior to immunological and liquid chromatographic quantification.

\section{Materials and Methods}

Materials

Chemicals

The organic solvents, methanol and acetonitrile, were of analytical grade and purchased from Merck (Darmstadt, FRG). Radioactive steroids and peptide hormones were purchased from DuPont-NEN (Boston, USA). 


\section{Solvents}

We used the following solvents for sample clean up: methanol, acetonitrile. de-jonized water, $50 \mathrm{mmol} / \mathrm{l}$ trifluoroacetic acid, $20 \mathrm{mmol} / \mathrm{l} \mathrm{NaOH}$ and $20 \mathrm{mmol} / \mathrm{l} \mathrm{HCl}$. Water was further purified by passage through Sep-Pak $C_{18}$ cartridges (Waters Associates, Königstein/Taunus, FRG). Acetonitrile and methanol were used without further purification.

\section{Instrumentation}

The complete sample extracting system, outlined in figure 1 , includes the following units: the sample loading unit, the sample clean up unit and the controlling microprocessor unit.

The sample loading unit consists of a sampler (S) and a peristaltic pump (PP) both from an AutoAnalyzer I (Technicon Instruments Corp., Tarrytown, NY 10591, USA) and a pneumatically driven six way valve (HV1) (Model 7010; Rheodyne Inc., Berkeley, CA 94710, USA).

The sample clean-up unit consists of a motor-driven twelve way valve (V1) (Latek Ltd., Heidelberg, FRG), a high pressure pump (P) (EIdex Laboratories, California 94025, USA), a sixway valve (HV2) (Model 7010, Rheodyne), a Sep-Pak cartridge (C) (Water Associates) and a fraction collector (FC) (LKB 2070 Ultro Rac II).

The microprocessor was from Izumi Denki Corp., Osaka, Japan.

\section{Methods}

The following analytical steps are run automatically and are time-controlled by the microprocessor.

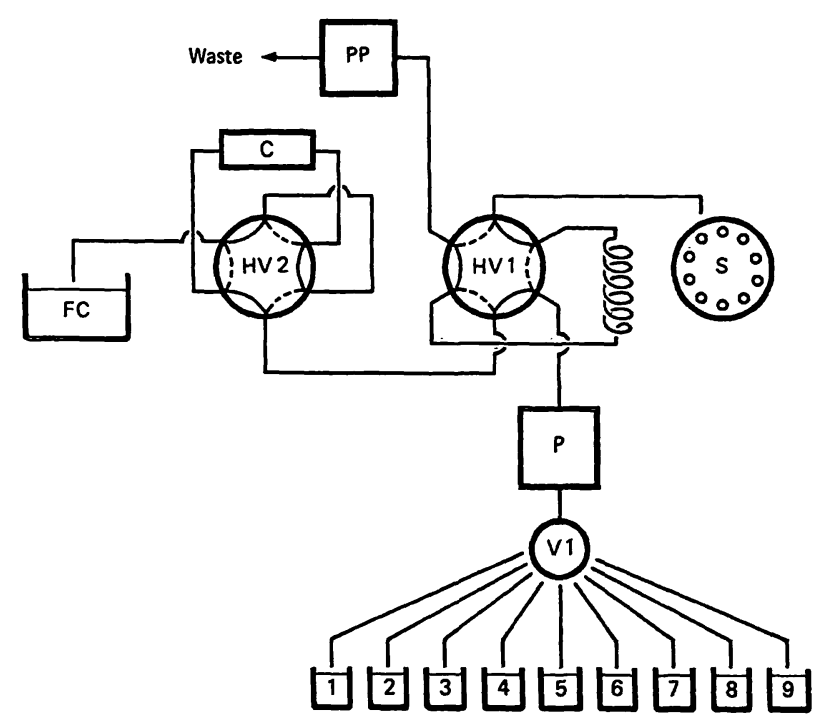

Fig. 1. Flow diagram of the fully automated clean-up device. Abbreviations: sampler (S), peristaltic pump (PP), motor-driven twelve way valve (V1), high pressure pump (P), six-way valves (HV1 and HV2), Sep-Pak cartridge (C), fraction collector (FC). Valves HV1 and HV2 are shown in position I. The broken lines indicate position II.

Solvents and bottles: water in 1; trifluoroacetic acid in 2; methanol-trifluoroacetic acid (20/80 by vol) in 3 ; methanol-water $(20 / 80$ by vol) in 4 ; methanol- $\mathrm{NaOH}$ $(35 / 65$ by vol) in 5 ; methanol- $\mathrm{HCl}(35 / 65$ by vol) in 6 ; methanol-water ( $40 / 60$ by vol) in 7 ; methanol in 8 ; acetonitrile-trifluoroacetic acid $(80 / 20$ by vol) in 9 .
Step 1

Urine or serum $(0.5 \mathrm{ml})$ is transfered from the sampler into the sampling loop of the sampling unit by activation of the peristaltic pump (HV1 in position I).

\section{Step 2}

The sampling loop is switched into the clean-up unit (HV1 in position II); the pump is activated to deliver water from bottle 1; the sample passes through the Sep-Pak cartridge; all lipophilic compounds are adsorbed and polar compounds are eluted.

\section{Step 3}

a) Steroids: For imunoassay purposes, lipophilic compounds more polar than steroids are washed out by delivering trifluoroacetic acid solution from bottle 2 for $1 \mathrm{~min}$, methanol-trifluoroacetic acid (20/80 by vol) from bottle 3 for 2 min and methanol-water (20/80 by vol) from bottle 4 for $1 \mathrm{~min}$.

For liquid chromatographic purposes, the cartridge is washed with trifluoroacetic acid from bottle 2 for $1 \mathrm{~min}$, followed by methanol- $\mathrm{NaOH}$ ( $35 / 65$ by vol) from bottle 5 for $2 \mathrm{~min}$, methanol- $\mathrm{HCl}(35 / 65$ by vol) from bottle 6 for $1 \mathrm{~min}$ and methanolwater ( $40 / 60$ by vol) from bottle 7 for $1 \mathrm{~min}$.

b) Peptides: For immunoassay purpose, all lipophilic compounds more polar than peptide hormones were washed out by delivering trifluoroacetic acid solution from bottle 2 for 2 min followed by methanol-trifluoroacetic acid from bottle 3 for $2 \mathrm{~min}$.

\section{Step 4}

a) Steroids: All steroids are eluted by delivering methanol from bottle 8 for $3 \mathrm{~min}$

b) Peptides: Peptides are eluted by delivering acetonitrile-trifluoroacetic acid ( $80 / 20$ by vol) from bottle 9 for $3 \mathrm{~min}$.

\section{Step 5}

Valve HV2 is switched into position II and acetonitrile-trifluoroacetic acid is delivered from bottle 9 for $2 \mathrm{~min}$. All residual material more lipophilic than the steroids or peptides is eluted from the cartridge in "back-flush" mode into the waste.

\section{Step 6}

Valve HV2 is switched into position I and pure water is delivered for 2 min to equilibrate the matrix of the cartridge, thereby preparing it for adsorption of the next sample.

Prior to clean-up of steroids, serum samples were acidified with $100 \mathrm{mmol} / 1$ of $\mathrm{HCl}(1 / 1$ by vol). For peptide clean-up, different dissociating diluents were studied. In the recovery studies, all fractions eluting from the cartridge and corresponding to the steps 1 to 6 were collected and measured for radioactivity to monitor the course of loss of the analytes.

For further immunological quantification, the steroid- or peptide-containing eluates are rapidly evaporated using a vacuated centrifuge. The residues are redissolved in immunoassay buffer ready for immunological assay.

For liquid chromatographic assay, the methanolic, steroidcontaining eluate (step 4) was evaporated to dryness, redissolved in acetonitrile-water (20/80 by vol) and subjected to high performance liquid chromatography (HPLC). The following HPLC-system was used: column $(250 \times 4 \mathrm{~mm})$ packed with ODS-silica; solvent: a gradient of 20 to $32 \%$ acetonitrile in water; flow rate $1.3 \mathrm{mil} / \mathrm{min}$; detection at $254 \mathrm{~nm}$. 


\section{Results}

The efficiency of the present extraction technique with respect to overall recovery, precision and reliability was studied in serum or urine samples equilibrated with about $180 \mathrm{kBq}$ of tritiated steroid or ${ }^{125} \mathrm{I}$ peptide. Results of recovered radioactivity in the final eluate (step 4) are shown in table 1 and 2. Except for calcidiol, the recovery is almost complete for all steroids studied. The lower recovery of tritiated calcidiol was due to its partial elution during the loading phase of the serum sample (step 2), thus indicating that the acid conditions applied here were insufficient to completely prevent protein-calcidiol binding. However, for all steroids, including calcidiol, precision is such that internal calibration of individual losses is not necessary.

For monitoring overall recovery of peptides, different sample diluents were studied. Although precision of recovery was similar to that found for steroids, absolute recovery depends distinctly on the individual

Tab. 1. Overall recoveries (step 4) of ${ }^{3} \mathrm{H}$-steroids from serum and urine using automatic extraction.

\begin{tabular}{llrll}
\hline Steroid & Matrix & $\mathrm{n}$ & CV & $\begin{array}{l}\text { Mean } \\
\text { recovery } \\
(\%)\end{array}$ \\
\hline Cortisol & Serum & 10 & 1.19 & 99.3 \\
& Urine & 10 & 1.01 & 99.6 \\
Oestriol & Serum & 10 & 1.63 & 94.6 \\
& Urine & 10 & 1.44 & 97.8 \\
11-Deoxycortisol & Serum & 8 & 0.97 & 99.3 \\
Aldosterone & Serum & 9 & 1.09 & 98.4 \\
Testosterone & Serum & 9 & 0.72 & 98.3 \\
Progesterone & Serum & 9 & 1.55 & 98.3 \\
Calcidiol & Serum & 9 & 3.17 & 82.0 \\
\hline
\end{tabular}

Serum samples were diluted with $100 \mathrm{mmol} / 1 \mathrm{HCl}(1 / 1$ by vol).

Tab. 2. Overall recoveries (step 4) of ${ }^{125}$ I-peptides from serum using automatic extraction.

\begin{tabular}{|c|c|c|c|c|}
\hline Peptide & Diluent & $\mathbf{n}$ & $\begin{array}{l}\text { CV } \\
(\%)\end{array}$ & $\begin{array}{l}\text { Meañ } \\
\text { recovery } \\
(\%)\end{array}$ \\
\hline Gastrin & $\begin{array}{l}50 \mathrm{mmol} / \mathrm{l} \mathrm{tri-} \\
\text { fluoroacetic acid } \\
\cdot 100 \mathrm{mmol} / \mathrm{l} \mathrm{H} \overline{\mathrm{Cl}} \\
\text { water }\end{array}$ & $\begin{array}{r}10 \\
6 \\
6\end{array}$ & $\begin{array}{l}1.27 \\
1.12 \\
2.76\end{array}$ & $\begin{array}{l}88.0 \\
70.1 \\
76.2\end{array}$ \\
\hline Glucagon & $\begin{array}{l}50 \mathrm{mmol} / \mathrm{l} \mathrm{tri-} \\
\text { fluoroacetic acid } \\
100 \mathrm{mmol} / \mathrm{HCl} \\
\text { water }\end{array}$ & $\begin{array}{r}10 \\
6 \\
6\end{array}$ & $\begin{array}{l}3.07 \\
2.85 \\
3.21\end{array}$ & $\begin{array}{l}88.7 \\
72.5 \\
76.5\end{array}$ \\
\hline Insulin & $\begin{array}{l}50 \mathrm{mmol} / 1 \mathrm{tri}- \\
\text { fluoroacetic acid } \\
100 \mathrm{mmol} / \mathrm{HCl} \\
\text { water }\end{array}$ & $\begin{array}{r}10 \\
6 \\
6\end{array}$ & $\begin{array}{l}6.05 \\
5.31 \\
7.41\end{array}$ & $\begin{array}{l}79.5 \\
66.5 \\
89.4\end{array}$ \\
\hline
\end{tabular}

peptide and also on the sample diluent. Thus, for gastrin and glucagon, recovery is highest, when 50 $\mathrm{mmol} / \mathrm{l}$ of trifluoroacetic acid is used as diluent, whereas insulin is maximally recovered, when water is used. Because of the good precision, internal calibration is unnecessary, even for peptide quantification.

Memory effects were studied in water samples run after the clean-up of iodinated insulin and tritiated cortisol. It was found to be less than $0.5 \%$.

The clean-up efficiency for liquid chromatographic purposes was studied by the extraction of cortisol from a normal serum sample prior to liquid-chromatographic quantification. Figure 2 a depicts the chromatogram obtained after the sample clean-up procedure applied for immunoassay purposes. Under these conditions, the cortisol peak is not clearly distinguishable from unspecifically absorbing compounds. Additional prewashing with alkaline and acidic solvents produces a clearly discernible cortisol peak (fig. $2 \mathrm{~b}$ ). This purification effect results from the elimination of ionizable phenolic, acidic and basic compounds, finally leaving only neutral substances similar to cortisol on the cartridge.

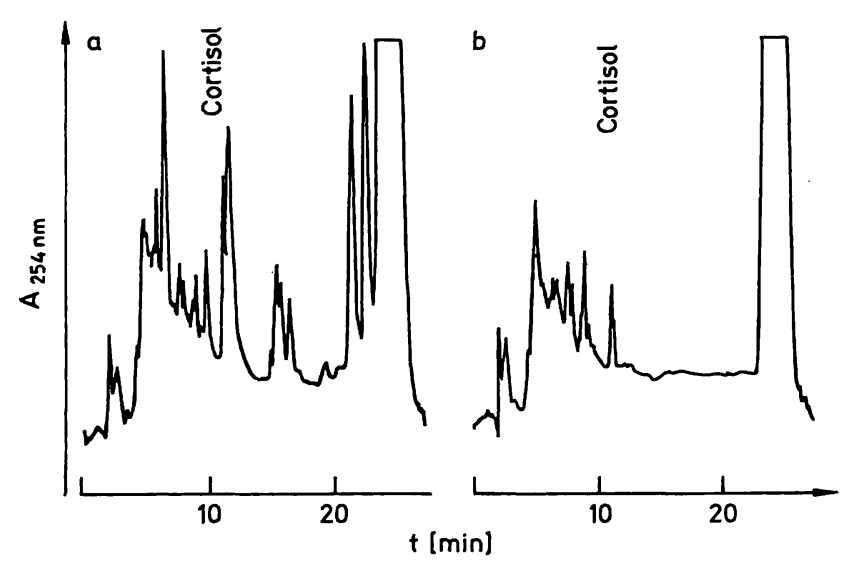

Fig. 2. Chromatograms of cortisol automatically cleaned up from serum using a simple extraction (a) and a more extensive prepurification (b) mode.

The time necessary for cleaning up one sample is 12 min. Thus, in overnight operation, 120 samples can be processed within one working day.

More than 100 samples, serum or urine, can be cleaned up for immunological assay with a single cartridge, without loss of efficiency. However, when alkaline and acidic solvents are used for washing, only $\mathbf{5 0}$ samples can be handled. This is due to slow solvolysis of the silica matrix by the alkaline conditions. The use of alkaline-resistant material, such as PRP 1 from Hamilton, may circumvent this effect. 


\section{Discussion}

Recently, there have been many efforts to automate sample clean-up procedures, especially prior to liquid-chromatographic quantitation $(10,11)$. All these techniques are based on the principle of columnswitching inaugurated by Huber et al. (12) and Erni et al. (13). The most advanced automated systems developed hitherto are the AASP ${ }^{\mathrm{TM}}$ system from Varian Ltd. and the auto-sampling injector from Gilson Ltd.

In the AASP ${ }^{\mathrm{TM}}$ system, samples are first loaded and cleaned up on specially designed cartridges using a separate Vac Elut ${ }^{\mathrm{TM}}$ module. Thus prepared, the cartridges are then included in the line of an automatic liquid chromatographic device (14). For liquid chromatographic purposes, this system provides the advantage of on-line injection of analytes from an already prepared cartridge. For immunological purposes, it has no significant advantages over the different manual or semi-automated cartridge techniques already widely used. The main disadvantage, both for liquid-chromatographic and immunological purposes, is the one-way use of cartridges, which renders it very costly.

The auto-sampling injector from Gilson Ltd. replaces the sample loop of a normal injector device by a small column thus also allowing the loading of larger samples. The injection column can be used for several injections. However, samples to be injected must be effectively cleaned-up prior to injection. Therefore, crude biological samples; e. g. $0.5 \mathrm{ml}$ of serum, cannot be processed by this technique.

\section{References}

1. Lantz, R.K. \& Eisenberg, R. B. (1978) Clin. Chem. 24, $821-824$.

2. Wehner, R. \& Handke, A. (1979) Clin. Chim. Acta 93, $429-431$.

3. Bamberg, E., Möstl, E. \& Hassan, N. D. (1980) Clin. Chim. Acta $108,479-882$.

4. Eriksen, P. B. (1981) Clin. Chem. 21, 1926-1928.

5. Schöneshöfer, M. \& Fenner, A. (1981) J. Clin. Chem. Clin. Biochem. 19, $71-74$.

6. Shackleton, C.H.L. \& Whitney, J.O. (1980) Clin. Chim. Acta $107,231-243$.
In principle, the hardware components used in the technology described here are also integrated parts of commercially available systems, and, in this sense, they are not new. To our knowledge, however, no data have so far been published on the efficiency of an automated technique using regenerated "one-way" cartridges, which can also concomitantly process large volumes of crude biological fluids.

The present sample clean-up technique includes all the advances of these recent automated techniques. In addition, it provides the following further advantages: manual manipulations are reduced to the transfer of the crude or acidified, centrifuged sample into the automatic sampler; the electronically controlled unit of the clean-up device provides unattended operation even overnight; even large amounts of crude samples can be processed; the regeneration of a normal Sep-Pak cartridge provides economical operation in comparison with the use of the relatively expensive "one-way" cartridges handled either in the manual or automatic mode; the costs of organic solvent necessary for regeneration amount to about $5 \%$ of the price of a "one-way" cartridge; the overall recovery and precision is better than those of the manual liquid-liquid and "solid-phase" extraction techniques $(1-9)$ and is equivalent to those of the advanced automatic sampling techniques $(10,11)$.

The applicability of the present technique has been studied for steroid and peptide molecules, because these analytes represent a special challenge for sample clean-up. Principally, this clean-up technique is also applicable to all low-molecular weight solutes, which have a significant adsorptivity to reversed-phase matrices. This is the case, for example, in the wide field of drug analysis.

7. Narasimhachan, N. (1981) J. Chromat. $225,189-195$.

8. Lee, D.P. \& Kindsvater, J.H. (1980) Anal. Chem. 52, $2425-2428$.

9. Andreolini, F., Corcia, A. D., Lagana, A., Samperi, R. \& Raponi, G. (1983) Clin. Chem. 29, 2076-2078.

10. Yago, L. (1985) Int. Lab. $18,40-51$.

11. Van Horne, K.C. \& Good, T. (1983) Am. Lab. 15, 116- 122.

12. Huber, J.F.K., van der Linden, R., Ecker, E. \& Oreans, M. (1973) J. Chromatogr. 83, 267-277.

13. Erni, F. \& Frei, R. W. (1978) J. Chromatogr. 149, 561 - 569.

14. Lim, C. K., Li, F. \& Peters, T. J. (1986) Int. Lab. 19, 60-67.
Prof. Dr. Dr. M. Schöneshöfer Institut für Klinische Chemie und Klinische Biochemie Klinikum Charlottenburg der Fủ Berlin Spandauer Damm 130 D-1000 Berlin 19 